\title{
Validation of the Mental IIIness Sexual Stigma Questionnaire (MISS-Q) in a sample of Brazilian adults in psychiatric care
}

\author{
Validação do Questionário de Estigma Sexual na Doença Mental (MISS-Q) \\ em uma amostra de adultos brasileiros em atendimento psiquiátrico \\ Milton Wainberg', Andrea Norcini Pala'2, Francine Cournos', Karen Mckinnon³
}

\begin{abstract}
Objective: We evaluated the psychometric properties of a new instrument "Mental Illness Sexual Stigma Questionnaire" (MISS-Q). Methods: We interviewed 641 sexually active adults (ages 18-80) attending public outpatient psychiatric clinics in Rio de Janeiro about their stigma experiences. Results: Nine factors were extracted through exploratory factor analysis (EFA) and labeled: 'individual discrimination by others'; 'staff willingness to talk about sexuality'; 'staff and family prohibitions'; 'sexual devaluation of self'; 'perceived attractiveness'; 'mental illness concealment'; 'perceived sexual role competence'; 'withdrawal'; and 'locus of socialsexual control'. 'Withdrawal' and 'locus of social-sexual control' showed poor psychometric properties and were excluded from further analysis. The remaining seven factors had high factorial loadings (.39 to .86), varying from sufficient to optimal reliability (Ordinal a ranged from .57 to .88), and good convergent and discriminant validity. Conclusions: The resulting MISS-Q is the first instrument assessing mental illness sexual stigma with demonstrated psychometric properties. It may prove useful in reducing stigma, protecting sexual health, and promoting recovery.
\end{abstract}

\section{Keywords}

Stigma, severe mental

illness, sexual and romantic relationships, psychometric assessment.

\section{RESUMO}

Objetivo: Avaliamos as propriedades psicométricas de um novo instrumento "Mental Illness Sexual Stigma Questionnaire" (MISS-Q; Questionário de Estigma Sexual na Doença Mental). Métodos: Entrevistamos 641 adultos sexualmente ativos (18 a 80 anos), frequentando clínicas psiquiátricas ambulatoriais públicas no Rio de Janeiro sobre suas experiências de estigma. Resultados: Foram extraídos nove fatores por meio da análise exploratória fatorial e rotulados: 'discriminação individual por parte de outros'; 'disposição pessoal para falar sobre sexualidade'; proibições pessoais e familiares; 'desvalorização sexual de si mesmo'; 'percepção de atratividade'; 'dissimulação da doença mental'; 'percepção da competência de papel sexual'; 'retirada'; e 'locus de sociosexual ao controle'. 'Retirada' e 'locus de controle social-sexual' mostraram propriedades psicométricas fracas e foram excluídos da análise posterior. Os sete fatores restantes tinham altas cargas fatoriais $(0,39$ a 0,86$)$, variando de suficiente até confiabilidade ótima (Ordinal a variou de ,57 a,88), e boa validade convergente

1 Columbia University Medical Center, New York State Psychiatric Institute. 2 HIV Center for Clinical and Behavioral Studies New York State Psychiatric Institute and Columbia University. 


\section{Palavras-chave}

Estigma, doença mental grave, relações sexuais e românticas, avaliação psicométrica. e discriminante. Conclusões: $\mathrm{O}$ resultante MISS-Q é o primeiro instrumento que avalia o estigma sexual da doença mental com propriedades psicométricas demonstradas. Pode ser útil na redução do estigma, proteção da saúde sexual e promoção à recuperação.

\section{INTRODUCTION}

Nearly twenty years ago, the Surgeon General of the United States identified stigma as "the most formidable obstacle to future progress in the arena of mental illness and health"1. Psychiatric patients continue to be stigmatized ${ }^{2,3}$ and experience detrimental effects and discrimination in multiple systems (e.g., education, housing, work-force, health, mental health, judicial) and in their social networks ${ }^{3,4}$.

Evidence suggests that labeling someone with mental illness influences sexuality and sexual behaviors as a contributor either to social and sexual isolation ${ }^{5,6}$ or to increased sexual risk behaviors ${ }^{7-9}$. Expectations of romantic and sexual rejection by the person labeled with mental illness can lead to reduced confidence, constricted social networks, depression, and low self-esteem ${ }^{3,9-11}$ and may interfere with achieving full potential for recovery ${ }^{12,13}$.

In a recent review of the existing instruments assessing mental illness stigma ${ }^{14}$, none measured mental illness stigma related to patients' romantic and sexual relationships. Avoidance of patient sexuality by mental health providers and researchers is not only a manifestation of stigma but also includes legitimate worries about the vulnerability of people with mental illness to such adverse outcomes such as coerced sex, nonconsensual sex, unplanned pregnancy, sexually transmitted infections and painful experiences of rejection by potential sexual partners. However, ignoring the sexual lives of people in psychiatric care is not only inconsistent with recovery but contributes to adverse health outcomes, including the sharply elevated rates of HIV infection found among people with mental illness compared to the general population in most regions where rates have been examined ${ }^{15,16}$.

Our investigation into mental illness sexual stigma originated with psychiatric outpatients in the U.S. ${ }^{6,7}$. It was explored through ethnographic and other developmental work in Brazi $\left.\right|^{9,17,18}$, resulting in a questionnaire with good testretest reliability $(k=.75)^{17}$, that has been used in a U.S. pilot study of adolescents with psychiatric disorders ${ }^{19}$. However, the factorial structure and validity of the instrument have not been determined. The Mental IIIness Sexual Stigma Questionnaire (MISS-Q) applies modified labeling theory ${ }^{20}$, which postulates that stigma influences behavior through social environmental and social psychological processes. Once labeled with mental illness (societal stigma), the person experiences stigma via three mechanisms: 1) individual discrimination - other individuals engage in overt practices of discrimination against the stigmatized individual; 2) structural discrimination - institutional practices and policies work against the stigmatized group; and 3) social psychological processes - the stigmatized person's own perceptions of the negative stereotypes attributed to the undesirable trait (sometimes referred to as internalized stigma or self-stigma) - and expected discrimination ${ }^{10}$. The MISS-Q was developed to measure these three mechanisms but its items have not yet been empirically confirmed through exploratory factor analysis.

The aim of this study was to identify latent factors underlying the MISS-Q and to test their psychometric properties (i.e., reliability and validity) in a sample of Brazilian adults in psychiatric care.

\section{METHODS}

\section{Sample and design}

A sample ( $N=641)$ of sexually active adults in psychiatric care was recruited from eight public outpatient psychiatric clinics in Rio de Janeiro between June 2007 and November 2009 as part of an HIV prevention trial (R01 MH65163: Wainberg). To evaluate the MISS-Q, we analyzed data collected at baseline by trained interviewers.

\section{Measures}

MISS-Q

The MISS-Q is a face-to-face interview containing 33 items. The first six items were constructed to assess Individual discrimination experiences including five general mental illness individual discrimination items (e.g. "How often have you been made fun of because you have a mental illness?"; "Has anyone ever called you 'crazy, 'loca,' or 'nuts'?"); and one sexual relationship-specific item.

Ten items refer to structural discrimination, including the willingness of mental health workers to discuss sexuality with patients (e.g. "Staff members make patients feel comfortable to talk about sexuality and sex issues."), and messages of prohibition about sexual activity from staff and family members (e.g. "How often has someone in your family ever said that since you are a user of mental health services you should not have sex?").

Seventeen items assess Social psychological processes, which comprises further sub-dimensions including 
devaluation, coping, attractiveness and locus of social-sexual control. 'Devaluation' captures perceptions those with mental illness have of others' disregard and rejection of their sexuality (e.g. "Most people don't show interest in having a romantic or sexual relationship with someone who has a mental illness"). 'Coping' focuses on avoidance of or willingness to directly deal with mental illness stigma (e.g. "You hide the fact that you have been diagnosed with a mental illness from people you are interested in having a romantic or sexual relationship with"). 'Attractiveness' elicits internalized perceptions (e.g. "Having a mental illness makes you feel less attractive than other women/men"). 'Locus of social-sexual control' prompts for choice in sexual relationships (e.g. "In order to be sexually active, you always do what other people ask of you"). All MISS-Q items had 4-point Likert-type response options (0 never; 1 - rarely; 2 - sometimes; 3 - often). The one sexual item in the Individual discrimination component of the interview "How many of the people you have wanted to have a romantic or sexual relationship with said they didn't want to be involved with you because you were a user of mental health services?" was rated on 4-point Likert-type scale (0 none; 1 - some; 2 - most; 3 - all).

\section{Divergent validity measure}

HIV knowledge was assessed using the item "Pulling out the penis before a man climaxes/cums keeps a woman from getting HIV during sex", rated on a Yes -1 / No -0 scale ${ }^{21}$.

\section{Data analysis}

Descriptive statistics (i.e. mean and standard deviation [SD], and skewness, kurtosis, and Shapiro-Wilks test to assess variables' distribution) and correlational analyses were performed with SPSS 2322. Exploratory Factor Analysis (EFA - Quartimin oblique rotation) was conducted in Mplus 7.323 to assess the dimensionality of the MISS-Q. Weighted Least Squares adjusted Mean and Variance (WLSMV) estimation was used because the MISS-Q items were analyzed as ordinal variables ${ }^{23,24}$. First, we determined the maximum number of factors to retain using the Kaiser criterion (eigenvalue $>$ $1)^{25}$. Second, the factorial models were compared through the Root Mean Square Error of Approximation (RMSEA), Comparative Fit Index (CFI) and Tucker-Lewis Index (TLI). RMSEA $\leq .08$ or $\leq .05$, and CFI and TLI values $\geq .90$ or $\geq .95$ reflect acceptable and optimal fit, respectively ${ }^{26,27}$. Items with low loadings $(<.30)$ or statistically significant $(p<.05)$ crossloadings greater than .30 were considered weak indicators. Factor reliability was tested through ordinal alpha ${ }^{28}$ computed in R (http://www.R-project.org) psych package ${ }^{29}$. Similarly to Cronbach's alpha, ordinal alpha coefficients greater than .70 indicate good internal reliability ${ }^{30}$.

Convergent validity was assessed by testing the association (Pearson's $r$ coefficient) between the extracted factors with sexual- or romantic-related items and the extracted factor with non-sexual/romantic items. Divergent validity was evaluated by testing the association (Pearson's point-biserial coefficients) between the extracted sexual/ romantic MISS-Q factors with one item assessing HIV knowledge, which was not expected to be associated with mental illness sexual stigma experiences.

\section{RESULTS}

\section{Sample characteristics}

The sample (Table 1) consisted of women (58\%) and men $(42 \%)$ with a mean age of $42.54(S D=10.32$, range $=18$ 76) and was racially diverse (19.50\% black, $32.76 \%$ white, and $47.74 \%$ multiracial). Overall, $32.92 \%$ had a diagnosis of schizophrenia; $21.68 \%$ of bipolar disorder; $20.28 \%$ of nonpsychotic depression; $10.30 \%$ of depression with psychosis; $6.24 \%$ of anxiety disorders; $4.84 \%$ of psychosis not otherwise specified; $3.12 \%$ of schizoaffective disorder; and $0.62 \%$ had other diagnoses. More than half of the participants (66.61\%) reported being currently involved in a relationship, with $46.80 \%$ reporting being married.

Table 1. Characteristics of 641 psychiatric outpatients whose mental illness sexual stigma was assessed

\begin{tabular}{lcc}
\hline & \multicolumn{2}{c}{ Overall sample ( $=641)$} \\
\cline { 2 - 3 } & $\mathrm{n}$ & $\%$ \\
\hline Gender, count (\%) & 269 & 42.00 \\
Men & 372 & 58.00 \\
Women & $42.54(10.32)$ & \\
Age, mean (SD) & & \\
Ethnicity/race, count (\%) & 210 & 32.76 \\
White & 125 & 19.50 \\
Black & 306 & 47.74 \\
Multiracial & & \\
Sexual orientation, count (\%) & \\
Heterosexual & 589 & 92.89 \\
LGBT & 46 & 7.18 \\
Marital Status, count (\%) & & \\
Single & & 35.10 \\
Married & 225 & 46.80 \\
Separated or Divorced & 300 & 13.57 \\
Widow, Widower & 87 & 3.90 \\
\hline
\end{tabular}

${ }^{*} 4$ patients did not disclose their marital status; ${ }^{\S} 2$ patients did not disclose their sexual orientation and 4 did not answer the question.

\section{Exploratory Factor Analysis (EFA)}

Nine factors with eigenvalue greater than 1 and good indices of fit were initially extracted (see Table 2). Two 
items were dropped because of loadings lower than .30 ("You avoid approaching someone you are interested in having a romantic or sexual relationship with if you think he/she has negative attitudes about users of mental health services") or cross-loadings greater than .30 ("Now think about all the people you had or wanted to have a romantic or sexual relationship with. How many of them said they didn't want to be involved with you because you were a user of mental health services"). A second EFA was performed to test the factorial stability of the 9-Factor model, which showed optimal goodness-of-fit indices (RMSEA $=.03, \mathrm{CFI} / \mathrm{TLI}$.99/.97). The factors were labeled: 'staff willingness to talk about sexuality'; 'sexual devaluation of self'; 'staff and family prohibitions' (a measure of structural sexual discrimination); 'individual discrimination by others'; 'perceived attractiveness'; 'mental illness concealment'; 'perceived sexual role competence'; ' withdrawal; and 'locus of social-sexual control'.

Table 2. Models goodness-of-fit indices - EFA

\begin{tabular}{lccc}
\hline Model & RMSEA & CFI & TLI \\
\hline 1-Factor & .10 & .54 & .51 \\
2-Factor & .08 & .70 & .66 \\
3-Factor & .07 & .82 & .78 \\
4-Factor & .05 & .89 & .85 \\
5-Factor & .05 & .92 & .89 \\
6-Factor & .04 & .96 & .93 \\
7-Factor & .03 & .97 & .94 \\
8-Factor & .03 & .97 & .95 \\
9-Factor & .03 & .98 & .97 \\
\hline
\end{tabular}

\section{MISS-Q Reliability}

Internal consistency of the factors was evaluated using ordinal a coefficients. 'Individual discrimination by others' (5 items; ordinal $a=.88$ ), 'staff willingness to talk about sex' (4 items; ordinal $a=.76$ ), 'staff and family prohibitions' ( 6 items; ordinal $a=.88$ ), 'sexual devaluation of self' (4 items; ordinal $a=82$ ), and 'perceived sexual role competence' ( 4 items; ordinal $a=.73$ ) showed good internal consistency. Reliability coefficients of factors 'mental illness concealment' ( 2 items; ordinal $a=.57$ ) and 'perceived low attractiveness' ( 2 items; ordinal $a=.57$ ) were low, but the factor loadings were high or moderately high (ranging from .44 to .77; Table 3). Since the magnitude of the coefficient $a$ is influenced by the number of items analyzed, we decided to retain the two factors. The factors 'withdrawal' ( 2 items; ordinal $a=.42$ ) and 'locus of social-sexual control' ( 2 items; ordinal $a=.37$ ) showed poor reliability and low factor loadings and were excluded from further analysis, leaving seven MISS-Q factors.

\section{MISS-Q factors inter-correlation}

The results of the correlational analysis (Table 4) showed that patients with lower perceived attractiveness reported lower positive experiences of staff willingness to talk about sexuality, lower perceived sexual role competence, and greater mental illness concealment. Lower perceived attractiveness correlated with greater sexual devaluation of self and with experiences of rules that limit their sexual relationships from mental health professionals and family members. A more positive experience of staff willingness to talk about sexuality corresponded to greater perceived sexual role competence and disclosure of psychiatric diagnosis. Staff and family prohibitions were associated with lower sexual role competence.

\section{Convergent validity}

Convergent validity was investigated correlating the MISS-Q sexual/romantic factors with the individual discrimination factor (e.g., "How often have you been made fun of because you have a mental illness?"; "Has anyone ever called you 'crazy', 'loca', or 'nuts'?"). Four MISS-Q factors were significantly correlated with individual discrimination (Table 4): prohibitions by staff and family members, perceived attractiveness, perceived sexual role competence, and sexual devaluation of self.

\section{Divergent validity}

Divergent validity was evaluated correlating the seven MISS-Q factors with a single item assessing HIV knowledge. None of the MISS-Q factors showed a statistically significant correlation (Table 4).

\section{DISCUSSION}

We conducted the first exploratory factor analysis to empirically evaluate the latent factors of the MISS-Q. We developed this instrument using a theoretical 3-factor model corresponding to the stigma mechanisms described by Link and Phelan ${ }^{20}$ but this factoral structure was not previously investigated ${ }^{6,7}$. Our results indicated that 31 of the initial 33 items analyzed load on 9 factors. The factors 'individual discrimination by others', 'staff willingness to talk about sexuality', 'staff and family member prohibitions', 'sexual devaluation of self', and 'sexual role competence' had sound psychometric properties as demonstrated by high factor loadings and good internal reliability. The first factor, 'individual discrimination by others' assesses non-sexual/ romantic-related stigma, while the remaining six specifically assess sexual- or romantic-related stigma experiences of adults in psychiatric care. 
Table 3. Mental IIIness Sexual Stigma (MISS-Q) factor loadings and reliability

\begin{tabular}{|c|c|c|c|c|c|c|c|c|c|}
\hline & $\mathrm{F} 1$ & F2 & F3 & $\mathrm{F} 4$ & F5 & F6 & 57 & F8 & F9 \\
\hline Staff members are supportive when users talk about sexual issues & .76 & .04 & -.02 & -.01 & -.10 & .01 & -.04 & .06 & -.07 \\
\hline Staff members talk to users about how psychiatric medication can interfere in sexual functioning & .75 & -.04 & -.00 & .02 & .12 & .05 & .04 & -.01 & .14 \\
\hline Staff members make patients feel comfortable to talk about sexuality and sex issues & .64 & .08 & -.00 & -.03 & -.11 & -.05 & .04 & -.10 & -.02 \\
\hline $\begin{array}{l}\text { Staff members are supportive when clients express interest in having romantic or sexual } \\
\text { relationship }\end{array}$ & .56 & -.06 & .04 & -.01 & .07 & .06 & .02 & .12 & -.16 \\
\hline $\begin{array}{l}\text { Most people think that a person with mental illness doesn't get to be a good partner for someone } \\
\text { who doesn't have a mental illness }\end{array}$ & .02 & .82 & -.03 & .04 & -.03 & -.05 & .01 & -.07 & .13 \\
\hline $\begin{array}{l}\text { Most people when they find out someone is a user of mental health services, don't think that person } \\
\text { is sexually desirable }\end{array}$ & -.02 & .76 & -.04 & .03 & .03 & .02 & .00 & .12 & -.08 \\
\hline $\begin{array}{l}\text { Most people don't show interest in having a romantic or sexual relationship with someone who has } \\
\text { a mental illness }\end{array}$ & .06 & .69 & -.04 & -.04 & .10 & .01 & -.03 & -.07 & .13 \\
\hline $\begin{array}{l}\text { Most people think that users of mental health services should not have sexual or romantic } \\
\text { relationships }\end{array}$ & -.04 & .69 & .10 & .03 & -.03 & .02 & -.01 & .01 & -.25 \\
\hline $\begin{array}{l}\text { How often has a mental health care provider ever said that since you are a user of mental health } \\
\text { services you should not have a romantic or sexual relationship with other patients? }\end{array}$ & -.07 & .05 & .86 & -.04 & .01 & .04 & .16 & -.01 & .06 \\
\hline $\begin{array}{l}\text { How often has a mental health care provider ever said that since you are a user mental health } \\
\text { services you should not have sex? }\end{array}$ & .05 & -.06 & .86 & .02 & -.04 & -.05 & -.07 & -.14 & -.12 \\
\hline $\begin{array}{l}\text { How often has a mental health care provider ever said that since you are a user of mental health } \\
\text { services you should not have a romantic or sexual relationship with people who do not have a } \\
\text { mental illness? }\end{array}$ & -.01 & -.13 & .81 & .01 & -.13 & -.03 & -.06 & .13 & .05 \\
\hline $\begin{array}{l}\text { How often has someone in your family ever said that since you are a user of mental health services } \\
\text { you should not have a romantic or sexual relationship with other patients? }\end{array}$ & -.03 & .14 & .71 & .00 & .20 & .05 & .03 & .10 & .10 \\
\hline $\begin{array}{l}\text { How often has someone in your family ever said that since you are a user of mental health services } \\
\text { you should not have a romantic or sexual relationship with people who do not have a mental illness? }\end{array}$ & .09 & -.02 & .67 & .11 & .04 & .04 & -.13 & .02 & -.03 \\
\hline $\begin{array}{l}\text { How often has someone in your family ever said that since you are a user of mental health services } \\
\text { you should not have sex? }\end{array}$ & -.01 & .04 & .53 & .17 & -.01 & -.01 & -.11 & .03 & -.15 \\
\hline How often has someone ever called you 'crazy, ' Ioca', or 'nuts'? & .08 & -.04 & .00 & .85 & .13 & -.06 & .01 & -.14 & .05 \\
\hline $\begin{array}{l}\text { How often have you ever been treated differently from others after they learned that you had a } \\
\text { mental illness? }\end{array}$ & -.08 & .03 & -.05 & .84 & -.06 & .03 & .05 & .09 & -.03 \\
\hline $\begin{array}{l}\text { How often has someone ever ignored you or not taken seriously what you had to say because you } \\
\text { have a mental illness? }\end{array}$ & .01 & .05 & -.02 & .81 & -.07 & .04 & -.03 & .06 & -.06 \\
\hline How often has someone ever made fun of you because you have a mental illness? & .00 & .01 & .15 & .68 & .05 & -.00 & -.04 & -.10 & .01 \\
\hline $\begin{array}{l}\text { How often have you ever experienced people trying to take advantage of you because they know } \\
\text { that you a mental illness? }\end{array}$ & -.07 & .03 & .11 & .57 & -.03 & .04 & -.08 & .16 & .10 \\
\hline Having a mental illness has a negative impact on your opportunities for sexual relationships. & -.07 & .15 & -.03 & .12 & .54 & .05 & -.08 & .11 & -.01 \\
\hline Having a mental illness makes you feel less attractive than other women/men. & -.09 & .15 & .02 & .07 & .39 & -.22 & -.14 & .08 & -.14 \\
\hline $\begin{array}{l}\text { You explain what is mental illness to those you are interested in having a sexual or romantic } \\
\text { relationship with }\end{array}$ & -.07 & .00 & -.04 & -.06 & -.06 & .78 & -.02 & -.05 & -.09 \\
\hline $\begin{array}{l}\text { You hide the fact that you have been diagnosed with a mental illness from people you are interested } \\
\text { in having a romantic or sexual relationship with. }\end{array}$ & .05 & .03 & .06 & .10 & .10 & .57 & .05 & .20 & .25 \\
\hline $\begin{array}{l}\text { How good or successful you are in having a sexual or romantic relationship with someone you are } \\
\text { attracted to or interested in getting to know better. }\end{array}$ & .04 & .02 & .00 & -.02 & .15 & -.05 & .67 & .00 & -.01 \\
\hline How good or successful you are in being attractive to the person you are having a relationship with & -.02 & -.09 & -.04 & -.02 & .13 & .03 & .66 & -.16 & -.05 \\
\hline How good or successful you are in negotiating with your partner to get your sexual needs met. & .02 & .03 & .05 & .03 & -.23 & .01 & .64 & .02 & -.01 \\
\hline How good or successful you are in in helping your partner(s) meet his/her sexual needs. & .02 & .01 & -.05 & -.00 & -.17 & .03 & .63 & .14 & .04 \\
\hline $\begin{array}{l}\text { You feel more comfortable having a romantic or sexual relationship with people who also have used } \\
\text { mental health services. }\end{array}$ & .08 & -.01 & .05 & .02 & .06 & -.06 & -.04 & .59 & .02 \\
\hline In order to be sexually active, you always do what other people ask of you. & .01 & -.12 & .00 & -.04 & .21 & -.16 & .01 & .35 & -.25 \\
\hline You are the one who chooses the course of your sexual life. ${ }^{*}$ & .10 & .20 & -.02 & -.06 & -.14 & .10 & .04 & -.07 & .41 \\
\hline $\begin{array}{l}\text { You avoid approaching someone you are interested in having a romantic or sexual relationship with } \\
\text { if you think he/she has negative attitudes about users of mental health services. }\end{array}$ & -.10 & -.07 & .02 & .24 & -.03 & -.07 & -.03 & .12 & .33 \\
\hline
\end{tabular}

$a=$ ordinal alpha; MH mental health; ${ }^{*}$ reversed score; $F 1$ : Staff willingness to talk about sex; $F 2$ : Sexual devaluation of self; $F 3$ : Staff and family prohibitions; $F$ : Individual discrimination by others; $F 5$ Perceived attractiveness; $F 6$ : Mental illness concealment; F7: Perceived sexual role competence; F8: Withdrawal; and F9: Locus of social-sexual control. 
Table 4. Mental IIIness Sexual Stigma Factor correlations

\begin{tabular}{|c|c|c|c|c|c|c|c|c|}
\hline & Factors & 1 & 2 & 3 & 4 & 5 & 6 & 7 \\
\hline 1 & Individual discrimination by others & 1.00 & & & & & & \\
\hline 2 & Staff willingness to talk about sex & .03 & 1.00 & & & & & \\
\hline 3 & Staff and family sex prohibitions & $.30^{* * *}$ & -.01 & 1.00 & & & & \\
\hline 4 & Sexual devaluation of self & $.19^{* * *}$ & .02 & .03 & 1.00 & & & \\
\hline 5 & Perceived attractiveness & $.26^{* * *}$ & $-.09^{*}$ & $.10^{* *}$ & $.26^{* * *}$ & 1.00 & & \\
\hline 6 & Mental illness concealment & .07 & $-.11^{* *}$ & .04 & .03 & $.19^{* * *}$ & 1.00 & \\
\hline 7 & Perceived sexual role competence & $-.19^{* * * *}$ & $.10^{* *}$ & $-.14^{* * *}$ & -.06 & $-.24^{* * *}$ & -.08 & 1.00 \\
\hline DV & HIV knowledge $\mathrm{F}^{\ddagger}$ & .03 & -.01 & .07 & -.04 & -.06 & -.01 & .01 \\
\hline
\end{tabular}

${ }^{*} p<.05,{ }^{, *} p<.01,{ }^{* * *} p<.001$; Pearson's r coefficients; ${ }^{*}$ Pearson's point-biserial coefficient; $D V=$ divergent validity. criterion

The two factors 'perceived attractiveness' and 'mental illness concealment', each composed of two items, showed sufficient psychometric properties. Despite their low internal consistency, which was likely influenced by the small number of items comprising them, 'perceived attractiveness' and 'mental illness concealment' had high factor loadings (from .44 to .77$)$. In order to improve the psychometric properties of these two sub-scales, more items need to be developed.

The two factors 'withdrawal' and 'locus of social-sexual control', both composed of two items, showed poor psychometric properties (i.e. low internal consistency and factor loadings) and were not further analyzed. Qualitative and quantitative investigations should be conducted to determine if refinement of these sub-scales could improve their psychometric properties.

The seven MISS-Q factors (27 items) extracted were significantly inter-correlated, with good divergent validity, and most with good convergent validity. Staff and family prohibitions, sexual devaluation of self, perceived sexual role competence, and perceived attractiveness correlated with individual discrimination, which was used as a criterion variable. Overall, the results of the current study suggest that the MISS-Q has good psychometric properties.

Staff willingness to talk with patients about their sexuality was not associated with individual discrimination, though patients with lower perceived attractiveness reported less-positive experiences of staff willingness to talk about sexuality and with experiences of rules from mental health professionals and family members that limit their sexual relationships. A more positive experience of staff willingness to talk about sexuality corresponded to greater perceived sexual role competence and disclosure of psychiatric diagnosis. Staff and family prohibitions were associated with lower sexual role competence. Staff willingness to have nonjudgmental conversations about sexual aspects of patients' lives is associated with patients' sense of competence in potential sexual or romantic encounters and reduced concern about disclosure of a mental illness diagnosis to a potential sexual/romantic partner.
It is interesting that patients' willingness to confront mental illness stigma as part of a sexual relationship was independent of how much stigma patients had experienced in other contexts (individual discrimination). Having the courage to reveal having mental illness in a sexual relationship despite discrimination in other domains may be a marker of resilience to the stigmatizing beliefs of others. Additional items in the MISS-Q about managing stigma in sexual and romantic relationships might shed light on patients' successful strategies for coping with mental illness stigma more generally.

A recent review identified two approaches for reducing general internalized stigma (i.e., not specifically sexualor romantic-related): interventions aimed at changing stigmatizing beliefs and attitudes about mental illness, and interventions that do not challenge stereotypes but rather improve stigma-coping skills by enhancing self-esteem, empowerment, and help-seeking behavior ${ }^{31}$. Even though tackling stigmatizing beliefs might seem a more direct and logical way to reduce internalized stigma, an important number of stigma experts seem to favor the coping training approach $^{31}$. Future research should explore if reducing internalized stigma has, in turn, a positive effect on wellbeing, including sexual- or romantic-related aspects, or whether mental illness sexual stigma must be the direct focus of an intervention to reduce its negative impact. Creating interventions specific to reducing internalized sexual stigma would enable clinicians to identify critical windows during which intimate relationships and sexual health could become positive aspects of recovery. These interventions might also improve patients' ability to protect themselves from adverse sexual health outcomes by promoting a sense of competence in sexual and romantic encounters. Having a tool - the MISS-Q - to quantify mental illness sexual stigma is a first step toward identifying when it is hindering recovery and contributing to unsafe sexual behaviors.

Very few studies have been conducted examining how stigma affects the sexual lives of psychiatric patients. We believe the time has come to change this pattern. 


\section{Limitations}

This study contained some methodological limitations. Despite the thorough psychometric analysis, we did not test the stability of the seven-factor model over time using confirmatory factor analysis (CFA). Additionally, validity ultimately must be established by use of the instrument across diverse age groups (including youth), socioeconomic strata (those receiving care in private and public treatment settings), and geographic regions (taking into account culture, context, and meanings of stigma and related behaviors).

Refinement of the MISS-Q sub-scales is necessary to improve their reliability, e.g., building additional items to better capture the constructs underlying mental illness sexual stigma. Lastly, the psychometric properties of the questionnaire should be examined in samples of people receiving care in other settings and geographic regions. For example, in this Brazilian outpatient sample, nearly half of patients reported being married; by contrast, in studies examining sexual behavior in the context of HIV risk, the vast majority of sexually active participants were single ${ }^{16}$. Our own measures were informed by carefully conducted ethnographic and other developmental work ${ }^{9,17,18}$. Other aspects of patients' stigma experiences may impinge upon their sexual relationships and these are worth examining in future studies. Given the cultural underpinnings of stigma about mental illness, the salience and generalizability of MISS-Q items, factors, and their psychometric properties may require additional refinements when used in new settings.

\section{CONCLUSIONS}

In conclusion, the MISS-Q is the first instrument with demonstrated psychometric properties to assess mental illness sexual stigma among sexually active adults in psychiatric care. Though some modifications are required to improve the measurement of perceived attractiveness, mental illness concealment, withdrawal, and locus of social-sexual control as they relate to sexual and romantic relationships, the instrument possesses strong psychometric properties and may be useful to investigators working with those in psychiatric care. This instrument is ready to use bearing in mind that internalized mental illness sexual stigma is very complex, multi-factorial, and probably not limited to what we measured and what showed good psychometric properties in this version.

The MISS-Q captures diverse aspects of mental illness sexual stigma, with potential applicability to test its association with sexual risk behaviors, to evaluate the outcome of stigma-reduction interventions, and to broaden recovery approaches so that people with mental illness receive more support to pursue the very ordinary goal of having safe intimate relationships as part of leading a full life.

\section{INDIVIDUAL CONTRIBUTIONS}

Milton Wainberg - Study design and planning, data collection, literature review, interpretation of data, first draft and final version of the manuscript.

Andrea Norcini Pala - Dataset organization, statistical analysis, interpretation of data, preparation of the Methods and Results sections.

Francine Cournos - Study design and planning, data collection, literature review, interpretation of data, first draft and final version of the manuscript.

Karen McKinnon - Study design and planning, data collection, literature review, interpretation of data, first draft and final version of the manuscript.

\section{ACKNOWLEDGMENTS}

Dr. Norcini Pala is supported by a NIMH training grant (T32-MH19139 Behavioral Sciences Research in HIV Infection; Principal Investigator: Theodorus Sandfort, PhD).

\section{REFERENCES}

1. Satcher D. The Surgeon General's call to action to prevent suicide. Washington, DC US Public Heal Serv. 1999.

2. Gerlinger G, Hauser M, De Hert M, Lacluyse K, Wampers M, Correll CU. Personal stigma in schizophrenia spectrum disorders: a systematic review of prevalence rates, correlates, impact and interventions. World Psychiatry. 2013;12(2):155-64.

3. Link BG, Struening EL, Rahav M, Phelan JC, Nuttbrock L. On stigma and its consequences: evidence from a longitudinal study of men with dual diagnoses of mental illness and substance abuse. J Health Soc Behav. 1997;38(2):177-90

4. Ben-Zeev D, Young MA, Corrigan PW. DSM-V and the stigma of mental illness. J Ment Heal. 2010;19(4):318-27

5. Wright ER, Gayman M. Sexual networks and HIV risk of people with severe mental illness in institutional and community-based care. AIDS Behav. 2005;9(3):341-53.

6. Wright ER, Wright DE, Perry BL, Foote-Ardah CE. Stigma and the Sexual Isolation of People with Serious Mental IIIness. Soc Probl. 2007:54(1):78-98.

7. Collins PY, Elkington KS, von Unger H, Sweetland A, Wright ER, Zybert PA. Relationship of stigma to HIV risk among women with mental illness. Am J Orthopsychiatry. 2008;78(4):498-506.

8. Elkington KS, Hackler D, Walsh TA, Latack JA, McKinnon K, Borges C, et al. Perceived Mental Illness Stigma, Intimate Relationships, and Sexual Risk Behavior in Youth With Mental Illness. J Adolesc Res. 2012;28(3):378-404.

9. Wainberg ML, Alfredo González M, McKinnon K, Elkington KS, Pinto D, Gruber Mann C, et al. Targeted ethnography as a critical step to inform cultural adaptations of HIV prevention interventions for adults with severe mental illness. Soc Sci Med. 2007;65(2):296-308.

10. Link BG, Cullen FT, Struening E, Shrout PE. A Modified Labeling Theory Approach to Mental Disorders: An Empirical Assessment. Dohrenwend Source Am Sociol Rev. 1989;54(3): 400-23.

11. Rosenfield S, Vertefuille J, Mcalpine DD. Gender Stratification and Mental Health: An Exploration of Dimensions of the Self. Soc Psychol Q. 2000;63(3):208. 
12. Kelly PJ, Deane FP. Do therapeutic homework assignments address areas of need for individuals with severe mental illness? Community Ment Health J. 2011;47(2):194-200.

13. Maj M. The rights of people with mental disorders: WPA perspective. Lancet. 2011;378(9802):1534-5.

14. Brohan E, Slade M, Clement S, Thornicroft G. Experiences of mental illness stigma, prejudice and discrimination: a review of measures. BMC Health Serv Res. 2010;10(1):80.

15. Guimarães MDC, McKinnon K, Campos LN, Melo APS, Wainberg M. HIV risk behavior of psychiatric patients with mental illness: A sample of Brazilian patients. Rev Bras Psiquiatr. 2010;32(4):351-60.

16. Meade (S, Sikkema KJ. HIV risk behavior among adults with severe mental illness: A systematic review. Clin Psychol Rev. 2005;25(4):433-57.

17. Elkington KS, McKinnon K, Mann CG, Collins PY, Leu CS, Wainberg ML. Perceived mental illness stigma and HIV risk behaviors among adult psychiatric outpatients in Rio de Janeiro, Brazil. Community Ment Health J. 2010;46(1):56-64.

18. Pinto D de S, Mann CG, Wainberg M, Mattos P, Oliveira SB de. Sexuality, vulnerability to HIV, and mental health: an ethnographic study of psychiatric institutions. Cad Saúde Pública. 2007;23(9):2224-33.

19. Elkington KS, Hackler D, McKinnon K, Borges C, Wright ER, Wainberg ML. Perceived Mental Illness Stigma Among Youth in Psychiatric Outpatient Treatment. J Adolesc Res. 2012;27(2):290-317.

20. Link BG, Phelan JC. Conceptualizing stigma. Annu Rev Sociol. 2001;27(1):363-85.

21. Carey MP, Schroder KEE. Development and psychometric evaluation of the brief HIV Knowledge Questionnaire. AIDS Educ Prev. 2002;14(2):172-82.
22. IBM SPSS. Statistical Package for the Social Sciences. [0nline] Available at: http://www01.lbm.Com/software/analytics/spss. Vol 23. 2013.

23. Medina-Walpole A, Clark NS, Heppard B, Dannefer E, Hall W, McCann R. A user's guide to enhancing geriatrics in an undergraduate medical school curriculum: the ten-step model to winning the "geriatric game". Am Geriatr Soc. 2004;52(5):814-21.

24. Rhemtulla M, Brosseau-Liard PÉ, Savalei V. When can categorical variables be treated as continuous? A comparison of robust continuous and categorical SEM estimation methods under suboptimal conditions. Psychol Methods. 2012;17(3):354-73.

25. Kaiser HF. The application of electronic computers to factor analysis. Educ Psychol Meas. 1960;20(1):141-51.

26. Bentler PM. Comparative fit indexes in structural models. Psychol Bull. 1990;107(2): 238-46.

27. Hu L, Bentler PM. Cutoff criteria for fit indexes in covariance structure analysis: Conventional criteria versus new alternatives. Struct Equ Model A Multidiscip J. 1999;6(1):1-55.

28. Vulovic M, Rieger B, Van Vliet LJ, Koster AJ, Ravelli RBG. A toolkit for the characterization of CCD cameras for transmission electron microscopy. Acta Crystallogr Sect D Biol Crystallogr. 2010;66(1):97-109.

29. Choo AS. Impact of a stretch strategy on knowledge creation in quality improvement projects. IEEE Trans Eng Manag. 2011;58(1):87-96.

30. Guilford JP. Psychometric Methods. New York: McGraw-Hill, 1954.

31. Mittal D, Sullivan G, Chekuri L, Allee E, Corrigan P. Empirical Studies of Self-Stigma Reduction Strategies: A Critical Review of the Literature. Psychiatr Serv. 2012;63(10):974981. 